\title{
Value of V2G Frequency Regulation in Great Britain Considering Real Driving Data
}

Thingvad, Andreas; Calearo, Lisa; Andersen, Peter Bach; Marinelli, Mattia; Neaimeh, Myriam; Suzuki, Kenta; Murai, Kensuke

\section{Published in:}

Proceedings of 2019 IEEE PES Innovative Smart Grid Technologies Europe

Link to article, DOI:

10.1109/isgteurope.2019.8905679

Publication date:

2019

Document Version

Peer reviewed version

Link back to DTU Orbit

Citation $(A P A)$ :

Thingvad, A., Calearo, L., Andersen, P. B., Marinelli, M., Neaimeh, M., Suzuki, K., \& Murai, K. (2019). Value of V2G Frequency Regulation in Great Britain Considering Real Driving Data. In Proceedings of 2019 IEEE PES Innovative Smart Grid Technologies Europe [8905679] IEEE. https://doi.org/10.1109/isgteurope.2019.8905679

\section{General rights}

Copyright and moral rights for the publications made accessible in the public portal are retained by the authors and/or other copyright owners and it is a condition of accessing publications that users recognise and abide by the legal requirements associated with these rights.

- Users may download and print one copy of any publication from the public portal for the purpose of private study or research.

- You may not further distribute the material or use it for any profit-making activity or commercial gain

- You may freely distribute the URL identifying the publication in the public portal 


\section{Value of V2G Frequency Regulation in Great Britain Considering Real Driving Data}

\author{
Andreas Thingvad, Lisa Calearo \\ Peter B. Andersen, Mattia Marinelli \\ Department of Electrical Engineering \\ Technical University of Denmark \\ Roskilde, Denmark \\ \{athing,lica,pba,matm\}@elektro.dtu.dk
}

\author{
Myriam Neaimeh \\ School of Engineering \\ Newcastle University \\ Newcastle upon Tyne, UK \\ myriam.neaimeh@newcastle.ac.uk
}

\author{
Kenta Suzuki, Kensuke Murai \\ EV System Laboratory \\ Nissan Motor Co., Ltd. \\ Yokosuka, Kanagawa, Japan \\ \{ke-suzuki,ke-murai\}@mail.nissan.co.jp
}

\begin{abstract}
Electric Vehicles (EVs) can, when they are not used for driving, create value for the EV owner, by delivering ancillary services to the transmission system operator. Calculating potential earnings from grid services and charging strategies highly depends on the driving time, driving distance, and time spent at different locations. While few datasets describing EV usage exist, this work is based on one of the most extensive datasets gathered from 7,163 Nissan LEAFs. Using the real driving and charging data it was possible to calculate the value of a specific charging strategy for the individual EV. The EV dataset was used in a simulation based on British electricity transmission network operating codes and frequency measurement data. The outcome is the profit from frequency regulation for each $\mathrm{EV}$ in the data-set, which is found to range between 50 and $350 £$ /year, because of the large difference in the $\mathrm{EV}$ usage.
\end{abstract}

Index Terms-Ancillary Services, Battery degradation, Electric Vehicles, Frequency Control, Vehicle-to-Grid

\section{INTRODUCTION}

The research area of Vehicle-Grid Integration (VGI) deals simultaneously with addressing the self-induced adverse effects that the transportation sector may introduce in the system in terms of congestion and voltage issues, while also seeking to fully utilise Electric vehicles (EVs), to support a stable and economic power system based on renewables. Frequency Regulation is the service that has been deeply explored in connection with the existing dispatching strategies of EVs, as possibility of solving stability and economy problems [1]. It has been experimentally demonstrated that frequency regulation can be delivered by modulating the unidirectional charging flow, for a profit of $44 £ /$ year in the Nordic grid [2]. Especially the technical support of Vehicle-to-Grid (V2G), i.e. the support of bi-directional power-flow, aids the vehicles in supporting this category of services. Bidirectional V2G frequency regulation can in the Nordic grid give a 17 times higher profit than the unidirectional case [3], considering the external DC charger from [4], with a power capacity of $\pm 10 \mathrm{~kW}$.

The revenue from frequency regulation depends on many parameters such as electricity and regulation market prices, plugin hours, power capacity of the charger etc. [5]. In France EVs, with simplified trips only between home and work, are found to have a revenue of approximately $86 £$ /year [6], in Germany the average revenue is found to be $172 £$ /year [7]. It has been found that through analysing plugin and usage behaviour, it may be possible to assess and fully utilise the availability of the EVs without adverse effects to driving needs [8].

The typical availability of EVs to provide frequency regulation is provided by a large $(n=7163)$ data-set based on Nissan Leafs driving in the United States (US). To this end, the requirements and characteristics of the available frequency regulation products are described in Section II and the driving characteristics of real users are derived in Section III-A. To better understand the limits and cost of providing the service, is important parameters such as the frequency energy content and the EVs energy constraints which will ultimately influence the profit also carefully investigated in Section III. Finally the study describes the distribution of revenue and profit that an EV may receive in the GB before concluding the paper with a brief conclusion and discussion.

\section{Frequency Regulation in United Kingdom}

\section{A. Service Specification}

The Transmission System Operator (TSO) in the GB, National Grid Electricity System Operator (NGESO), procures Firm Frequency Response (FFR) reserve via an open market. FFR consist of 3 services, Primary, Secondary and High. In the case of an under-frequency event, the Primary should react within $2 \mathrm{~s}$ and deliver the full response within $10 \mathrm{~s}$ and sustain the response for 20 additional seconds. Within $30 \mathrm{~s}$ of the event, the Secondary should be started and maintain the response for 30 minutes. In the event of an over-frequency evenet the High Frequency Response should deploy its full response within 10 but maintain the response indefinitely, unless agreed otherwise. A frequency event is defined as when the frequency leaves the dead-band of $\pm 0.015 \mathrm{~Hz}$, and over and under-frequency event is when the frequency is higher than $0.015 \mathrm{~Hz}$ or lower than $-0.015 \mathrm{~Hz}$.

FFR has a minimum bid size of $1 \mathrm{MW}$, which can be from a single unit or aggregated from several smaller units. Primary, 
TABLE I

Characteristics of Frequency Regulation SERvices

\begin{tabular}{c|ccc} 
& $\begin{array}{c}\text { Response } \\
\text { time }\end{array}$ & $\begin{array}{c}\text { Duration of } \\
\text { activation }\end{array}$ & $\begin{array}{c}\text { Response max } \\
\text { @ Hz deviation }\end{array}$ \\
\hline Primary & $10 \mathrm{~s}$ & $30 \mathrm{~s}$ & $-0.2,-0.5,-0.8$ \\
Secondary & $30 \mathrm{~s}$ & $30 \mathrm{~min}$ & $-0.2,-0.5$ \\
High & $10 \mathrm{~s}$ & Indefinite & $0.2,0.5$
\end{tabular}

TABLE II

VOLUME OF TRADED SERVICE IN DIFFERENT PRICE RANGES FOR DECEMBER 2018 AND (2014)

\begin{tabular}{c|ccc}
$\begin{array}{c}\text { Price band } \\
{[\mathrm{f} / \mathrm{MW} / \mathrm{h}]}\end{array}$ & $\begin{array}{c}\text { Primary } \\
\text { Volume }[\mathrm{GW}-\mathrm{h}]\end{array}$ & $\begin{array}{c}\text { Secondary } \\
\text { Volume }[\mathrm{GW}-\mathrm{h}]\end{array}$ & $\begin{array}{c}\text { High } \\
\text { Volume }[\mathrm{GW}-\mathrm{h}]\end{array}$ \\
\hline 0 to 2 & $172(\mathbf{5 5})$ & $107(\mathbf{1 2 7})$ & $0(\mathbf{1 3 8})$ \\
2 to 4 & $25(\mathbf{2 0 7})$ & $0(\mathbf{4 8})$ & $351(\mathbf{6 3})$ \\
4 to 6 & $0(\mathbf{1 3})$ & $0(\mathbf{2 2 1})$ & $15(\mathbf{2 5 7})$ \\
6 to 8 & $0(\mathbf{1})$ & $0(\mathbf{0})$ & $0(\mathbf{8})$ \\
$>8$ & $0(\mathbf{0})$ & $0(\mathbf{0})$ & $2(\mathbf{2 6})$
\end{tabular}

Secondary and High are dynamic services where the response should be proportional to the frequency deviations with the maximum power at a deviation of either $0.2,0.5$ or $0.8 \mathrm{~Hz}$, as seen in Table I.

A combination of Primary, Secondary and High (PSH) service with a full response at $\pm 0.2 \mathrm{~Hz}$ is considered. A combined PSH delivery means that the EV responds symmetrically to over and under frequencies outside the deadband as shown in Eq. (1).

For a frequency value $f_{t}$ at time $t$, the normalised response $y_{t}$ is calculated as

$$
y_{t}=\left\{\begin{array}{rll}
-1, & \text { if } & f_{t}<49.8 \mathrm{~Hz} \\
\left(f_{t}-50\right) / 0.2, & \text { if } & 49.8 \mathrm{~Hz} \leq f_{t} \leq 49.985 \mathrm{~Hz} \\
0, & \text { if } & 49.985 \mathrm{~Hz} \leq f_{t} \leq 50.015 \mathrm{~Hz} \\
\left(f_{t}-50\right) / 0.2, & \text { if } & 50.015 \mathrm{~Hz} \leq f_{t} \leq 50.2 \mathrm{~Hz} \\
1, & \text { if } & f_{t}>50.2 \mathrm{~Hz}
\end{array}\right.
$$

The power required by the service provider at time $t$ is calculated as

$$
P_{t}=P_{\text {cap }} \cdot y_{t}
$$

\section{B. Contract and bidding}

The first business day of each month is the deadline for services starting on the following month i.e. January $1^{\text {st }}$ for service start on February $1^{\text {st }}$. The contract periods are based on the Electricity Forward Agreement (EFA) which means that it is traded in 6 four-hour blocks per day. Tenders must only start, and end, at the following times: 23:00, 03:00, 07:00, 11:00, 15:00 and 19:00.

NGESO makes a monthly report stating how much capacity purchased at each price range, which are shown in Table II for December 2018 and December 2014 in parenthesis. In this analysis it is assumed that PSH with full response at $\pm 0.2 \mathrm{~Hz}$ deviation is paid with $2+2+=8 \mathrm{f} / \mathrm{MW} / \mathrm{h}$, as it is the prices that Primary $(2 £ / M W / h)$, Secondary $(2 £ / M W / h)$ and High (4 $\mathrm{f} / \mathrm{MW} / \mathrm{h}$ ) mostly is traded at. The NGESO regulation prices are very low compared to the Nordic grid where the availability payment for primary frequency regulation on average is 20.7 $\mathrm{f} / \mathrm{MW} / \mathrm{h}$ [3]. It is unknown how the prices will change in the future.

\section{METHOD}

The driving data is gathered from EVs in the US. To justify the applicability of the US dataset to a GB case study, driving behaviour data from the UK and DK is analysed. The driving behaviour was similar across the 3 countries.

\section{A. Electric Vehicle Telematics Data}

The telematics data is collected in a data-set with all drive and charge events of 7163 Nissan $24 \mathrm{kWh}$ LEAFs in the US. It is collected from EVs where the owner has accepted to share data at the time of purchase, and corresponds to $50 \%$ of the sold EVs of the specific model. The data is anonymized but shows the daily behaviour of each EV during 2015 and 2016.

A time vector is generated for each EV with a value every 15 minute interval during the year, which specifies if the EV is driving or parked at the household, the work place or another location, as well as the the driving distance and the charging power.

The driving behaviour in the US is compared with a GB and Danish driving behaviour metrics to show that the findings are general. The national Danish Travel Survey is based on conventional vehicles in Denmark but it is found that the driving behaviour is similar. Fig. 2 shows the distribution of the accumulated driving distance for each $\mathrm{EV}$ in one year. The average driving distance is $17200 \mathrm{~km} / \mathrm{year}$ equal $47 \mathrm{~km} / \mathrm{day}$ which is a bit higher than in Denmark, where the average driving distance is $45 \mathrm{~km} /$ day [9] and in GB where it is 34 $\mathrm{km} /$ day [10].

The average driving time is 228 hours giving an average utilisation of $2.6 \%$, which is also the same in Denmark and GB.

In Fig. 1 is shown the group behaviour during a work day in 2016, as a representative day, not an hourly average. The blue line shows the share of the EVs that are driving during the day and the red line shows the share of the EVs that are charging simultaneously. The charging peak is very similar for every workday is but lower in the weekend. It can be seen that despite the data being from EVs with only $24 \mathrm{kWh}$ battery capacity, the simultaneous charging peak is only $18 \%$. From the driving curve, the rush hour peak times can be identified as 07:00 and 17:30, which are the same in Denmark [11].

Being personal vehicles parked $97.4 \%$ of the time, for the EVs this is a huge potential for utilising the battery capacity during the idle time. The EV is however only available for the grid when the owner plugs it in, which does not happen every day as seen in Fig. 1.

We are making the assumption that people are going to plug in their EV every time they park them (at home and at work); which is unlikely to be the case unless the users are properly incentivised to plug their EV. 


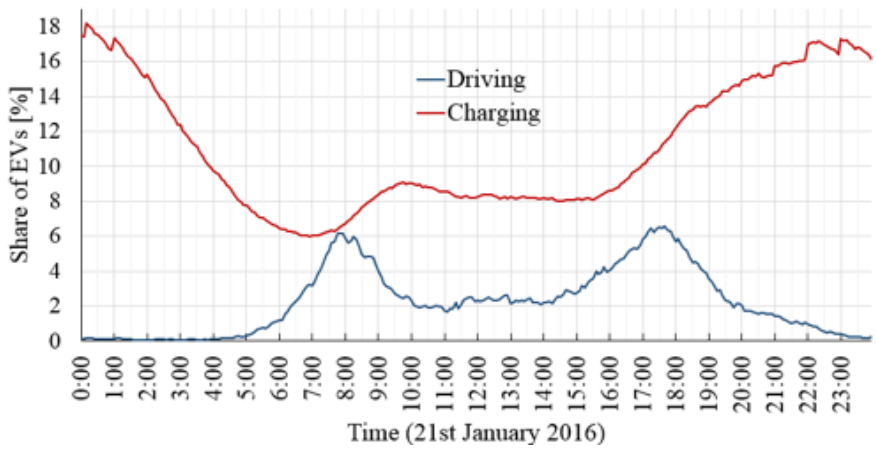

Fig. 1. Share of EVs driving and charging during Thursday $21^{\text {st }}$ of January 2016 .

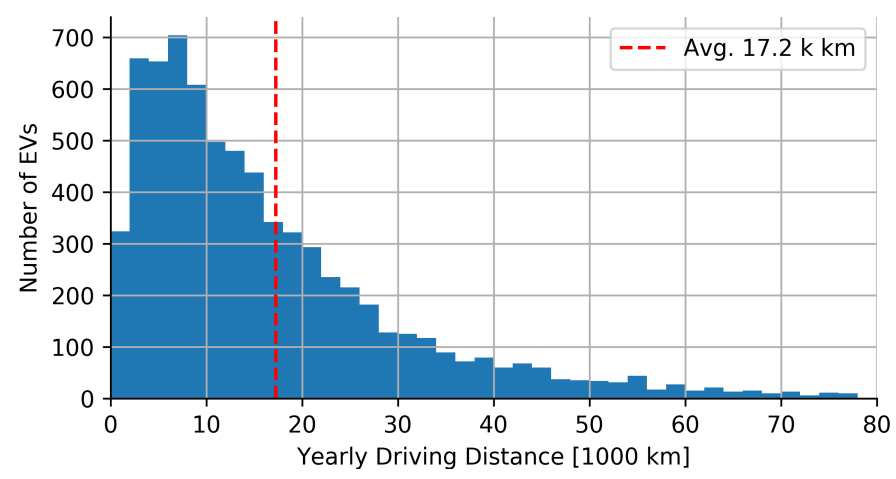

Fig. 2. Distribution of the yearly driving Distance.

\section{B. United Kingdom Spot Market Price Model}

In Fig. 3 is shown the spot prices every day of 2018, which has an average of $57 £ / \mathrm{MWh}$. When adding network tariffs and taxes the average domestic cost is $161 \mathrm{f} / \mathrm{MWh}$ while the industrial electricity cost only is $117 \mathrm{f} / \mathrm{MWh}$ [12]. A simple tariff model is made by calculating the difference between the average spot price and the average industrial electricity price, Tariff $_{\text {industry }}=117-57=60 \mathrm{f} / \mathrm{MWh}$. It is assumed that the energy consumption caused by conversion losses for service provision is paid with the industrial electricity price.

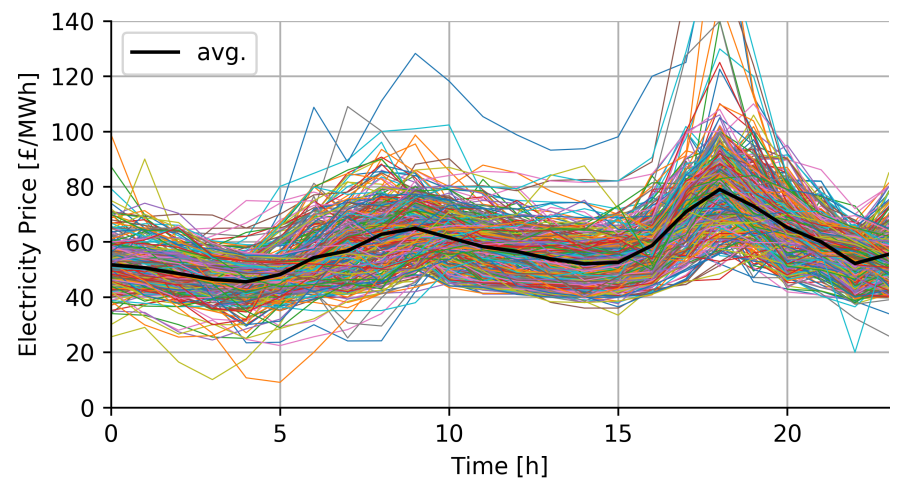

Fig. 3. GB spot market prices every day of 2018 .

\section{Energy Content of GB System Frequency}

When a storage resource is delivering PSH, it will either deliver or receive energy to or from the grid depending on if there is an under or over frequency. This is referred to as the energy content and can be calculated by integrating the frequency deviations during a certain period. The energy content is calculated for every 15-minute period of the year so it has the same time resolution as the consumption from driving and can be used to calculate the State of charge (SOC).

The following analysis is based on grid frequency measurements from GB power system during all of 2018 with a sample rate of $1 \mathrm{~s}$, measured by NGESO. The integration of frequency deviations of a given 15-minute period $n$, referred to as the energy content or energy bias of that period, is denoted by $e_{n}^{\text {bias }}$. For a sample rate of $t_{\mathrm{s}}=1 \mathrm{~s}$, the number of samples per 15 -minutes period is equal to $N_{p}=900$. The sum is divided with the number of samples per hour, $N_{h}=3600$ for a unit in $\mathrm{kWh}$. The per unit energy content (normalised per $\mathrm{kW}$ of regulation capacity), is given by

$$
e_{n}^{\text {bias }}=\frac{1}{N_{h}} \sum_{t=N_{p} \cdot(n-1)+1}^{n \cdot N_{p}} y_{t} \cdot t_{\mathrm{s}}
$$

The energy content of the GB frequency is a bit higher than in the North European power system (ENTSO-E Regional Group Nordic), which is known to have a very high energy content [13]. This is caused by the small size of the system and the large amount of renewable energy production. Because the full response is given for a deviation of $\pm 0.2 \mathrm{~Hz}$ and not $\pm 0.1 \mathrm{~Hz}$, which is the case in the Nordic grid, the variance of the experienced energy content is a bit lower. Fig. 4 shows the energy balance since the beginning of service provision for every day in 2018 assuming a 24-hour service period with $P^{\mathrm{r}}=10 \mathrm{~kW}$, without conversion losses. When adding the conversion losses the energy balance is moved to the negative side but the variance whihch is the main problem, remains the same. More than $99 \%$ of the cases ends up within \pm 20 $\mathrm{kWh}$, which indicates that the service can be delivered with an EV with a $40 \mathrm{kWh}$ battery and an initial SOC of $50 \%$ as the service rarely is being delivered continuously for such long periods.

\section{Capacity Payment}

Initially it is calculated how large a revenue the EVs can generate in one year if they deliver High regulation in all the EFA periods where they are parked during the whole 4-hour period. This is calculated without considering the energy storage constraints by assuming that there either is an available $\pm 10 \mathrm{~kW}$ V2G charger at the household or both at the household and the workplace and making the assumption that people are plugging the EV once they park.

\section{E. Energy model}

The next step is to model the SOC of the EVs. It is assumed that all the EVs have a battery capacity of $Q_{n}=40 \mathrm{kWh}$ like the 2018 model Nissan LEAF. The energy for driving in 


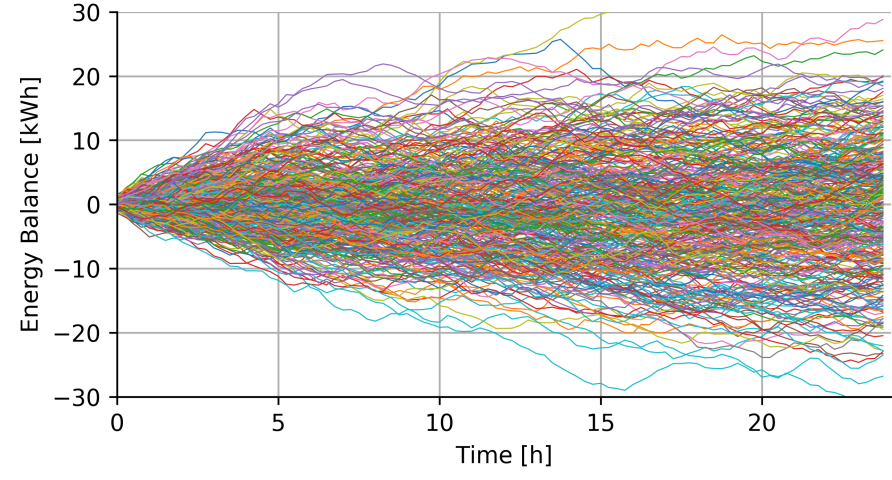

Fig. 4. Evolution of energy balance when delivering frequency regulation every day in 2018 with $P^{\mathrm{r}}=10 \mathrm{~kW}$ and no conversion losses.

period $n, E_{n}^{\text {drive }}$ is based on the driving distance of each trip considering a driving efficiency of $5 \mathrm{~km} / \mathrm{kWh}$. The charging, $E_{n}^{\text {charge }}$, is scheduled just before each trip, with a charge power of $10 \mathrm{~kW}$, in order to give maximum time for PSH. The EFA period where the EV is charging is not counted for PSH.

Because of the large energy content of PSH with $P^{\mathrm{r}}=10$ $\mathrm{kW}$ often results in energy constraint violations. By bidding $P^{\mathrm{r}}=8 \mathrm{~kW}$ and allocating a correcting power, $P^{\text {cor }}=2 \mathrm{~kW}$, the $\mathrm{PSH}$ range can either be $[-8$ to 8$],[-6$ to 10$]$ or $[-10$ to 6$]$ $\mathrm{kW}$, depending on the SOC. A regulation capacity of $P^{\mathrm{r}}=8$ $\mathrm{kW}$ is the maximum that does not result in SOC violations caused by the combination of the driving consumption and frequency energy content. A similar maximum of $7 \mathrm{~kW}$ is in Ref. [3], found for the Nordic Grid because of the more strict service requirements. The correcting power, $P^{\text {cor }}$, is applied when the energy balance, $\Delta E$ leaves the acceptable window during service provision. $\Delta E$ is the summarised energy received or delivered since the start of the simulation.

$$
E_{n}^{\mathrm{cor}}=\left\{\begin{aligned}
P^{\mathrm{cor}} & \text { if } \Delta E_{n}<-10 \mathrm{kWh} \\
-P^{\mathrm{cor}} & \text { if } \Delta E_{n}>10 \mathrm{kWh}
\end{aligned}\right.
$$

The contracted energy at period $n$, on the grid side of the charger is calculated as

$$
E_{n}^{\text {grid }}=E_{h}^{\text {charge }}+P_{n}^{\mathrm{r}} \cdot e_{n}^{\text {bias }}+E_{n}^{\text {cor }}
$$

It is assumed that there is a conversion loss of $10 \%$ in both directions. A constant efficiency of $\eta=0.9$, is assumed for all loading levels. The energy on the battery side, $E_{n}^{\text {bat }}$, will either be higher or lower than on the grid side depending on if the EV is discharging or charging.

$$
E_{n}^{\text {bat }}=\left\{\begin{array}{lll}
E_{n}^{\text {grid }} \cdot \eta & \text { if } \quad E_{n}^{\text {grid }}>0 \\
E_{n}^{\text {grid }} \cdot \frac{1}{\eta} & \text { if } \quad E_{n}^{\text {grid }}<0
\end{array}\right.
$$

The energy balance since the beginning of the simulation, $\Delta E$, is in $\mathrm{kWh}$ and calculated by integrating the positive and negative energy flows over time, where $E_{n}^{\text {bat }}$ and $E_{n}^{\text {drive }}$ never are nonzero at the same time. $\Delta E_{n}$ would finally need to be evaluated against the battery capacity and the initial SOC.

$$
\Delta E_{n}=\Delta E_{n-1}+\left(E_{n}^{\text {bat }}-E_{n}^{\text {drive }}\right)
$$

The cost of energy is calculated based on the spot price every hour + the industrial tariffs. The spot prices are the same for the whole hour even though the cost is calculated for each 15-minute.

$$
\text { Cost }=\sum_{n=0}^{366 \cdot 24 \cdot 4}\left(P_{n}^{\mathrm{r}} \cdot e_{n}^{\text {bias }}+E_{n}^{\mathrm{cor}}\right) \cdot\left(\operatorname{Spot}_{n}+\text { Tariff }_{\text {industry }}\right)
$$

\section{RESULTS}

\section{A. Pure Power Constraints}

The average yearly revenue of all the EVs considering $\mathrm{Pr}=$ $10 \mathrm{~kW}$ regulation in all the full EFA blocks parked at home and work is $390 £ / y e a r$ or only at home is $370 £ / y e a r$. The revenue ranges between 100 and 650 f/year, depending on how much the EV is driven. The full revenue can be obtained only if $\mathrm{V} 2 \mathrm{G}$ chargers are installed both at home and at work. However, to apply the most cost-efficient solution only service provision from the household will be considered.

\section{B. Power and Energy Constraints}

Fig 5 Shows the lowest, highest, $1^{\text {st }}$ and $99^{\text {th }}$ percentile of the energy balance of the $7163 \mathrm{EVs}$ every 15-minute of the year, when the EVs are affected by driving consumption, charging and energy content of the frequency with the suggested control strategy. The energy balance ranges between -10 and $+15 \mathrm{kWh}$, so for a $40 \mathrm{kWh} \mathrm{EV}$ with an initial SOC of $50 \%$ it corresponds to a SOC range of $10-35 \mathrm{kWh}$. The control strategy described in Eq. (4) tries to maintain it within $\pm 10 \mathrm{kWh}$ but if the regulation period is followed by a long drive, it will charge to a higher level to accommodate that consumption. This shows that it is a realistic charging and regulation strategy for an $\mathrm{EV}$ with that battery size.

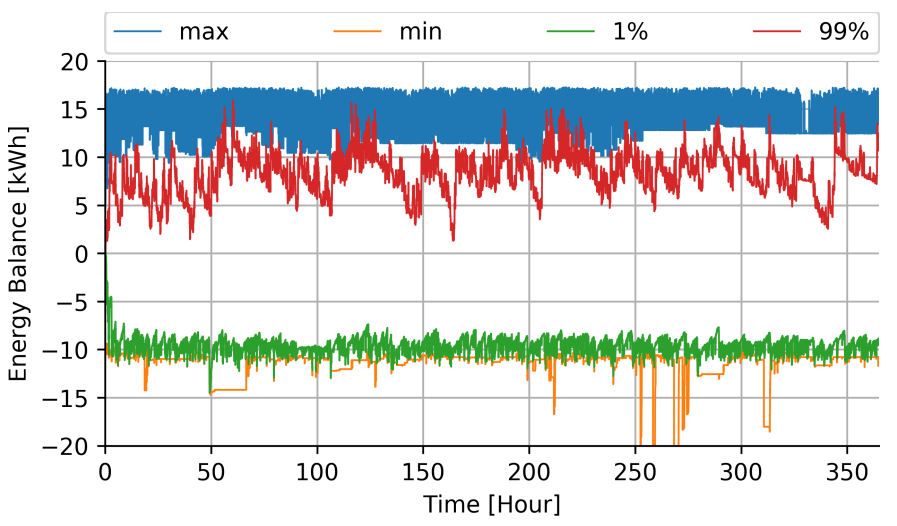

Fig. 5. Lowest, highest, $1^{\text {st }}$ and $99^{\text {th }}$ percentile of the energy balance, $\Delta E$ of the $7163 \mathrm{EVs}$, every hour of the year.

With time for charging allocated and a suitable bidding strategy found, it is possible to calculate a more realistic revenue for a bid of $P^{\mathrm{r}}=8 \mathrm{~kW}$, still with a capacity payment of $8 \mathrm{f} / \mathrm{MW} / \mathrm{h}$. The costs calculated in Eq. 8, are subtracted from the revenue to find the yearly profit for each EV. It is 
assumed that there is a net metering tariff scheme where the tariffs paid for charging are returned when discharging.

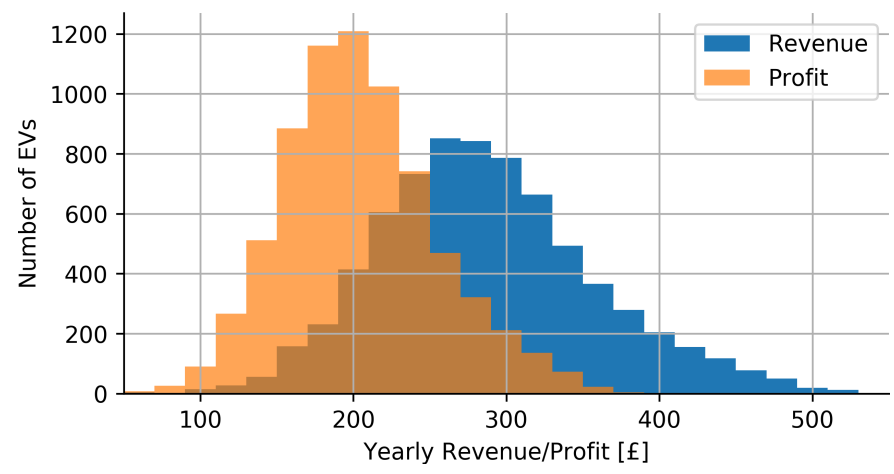

Fig. 6. Revenue (avg. $287.1 £ /$ year) and profit (avg. $204.4 £ /$ year)

The energy charged from the grid is paid with the electricity price of that hour including the low industrial tariffs with the average of $117 £ / \mathrm{MWh}$. The distribution of the revenue is shown in Fig. 6 and now spreads from 100 to $500 £ /$ year with an average of $287 £$ /year which is $83 £$ lower than the initial estimate. The EVs that provide HFR for most hours also has the highest energy loss, so the remaining profit after subtracting the individual charging cost has a lower spread between 80 and $380 £$ /year. On average the cost of energy losses is $30 \%$ of the revenue and result in an average profit of $204 £ /$ year. If the efficiency is increased to $95 \%$, it gives a reduction of the losses by $50 \%$.

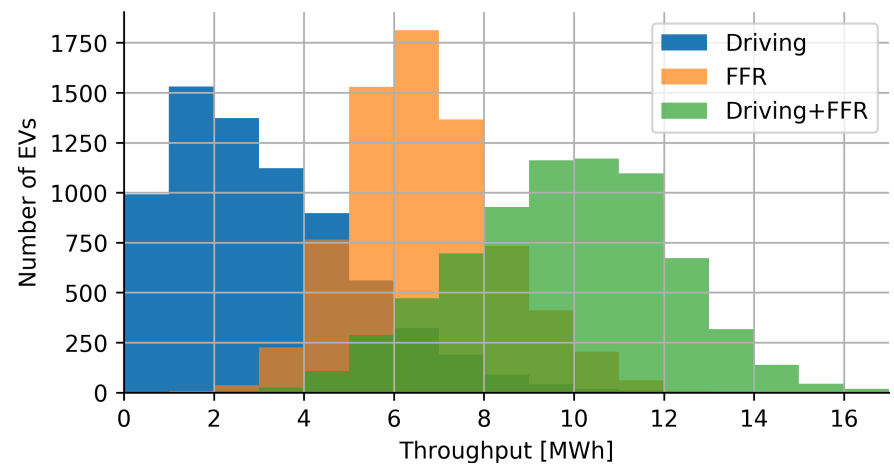

Fig. 7. Yearly energy throughput of the battery for driving (avg. 3.1 MWh), frequency regulation (avg. 6.7 MWh) and both (avg. 9.8 MWh)

The profit is calculated by only considering the cost for electricity and does not include the cost for installation and maintenance of the charger, as well as the added wear of the battery. In Fig. 7 is shown the distribution of the energy throughput caused by the individual users driving behaviour and the added throughput from delivering frequency regulation. The throughput increases on average $517 \%$ when going from just driving to also delivering frequency regulation. Considering a $40 \mathrm{kWh}$ battery, a throughput of $10 \mathrm{MWh}$ is only 125 full equivalent charge cycles per year. In [14], the battery degradation of a similar setup was modelled and it was found that 182 full equivalent cycles would only result in $0.4 \%$ increased capacity loss per year.

\section{CONCLUSION}

It is found that with a $40 \mathrm{kWh} \mathrm{EV}$, the service continuously can be delivered with $\pm 8 \mathrm{~kW}$ regulation capacity with \pm 2 $\mathrm{kW}$ in reserve for maintaining the SOC. There is a large variation in how much time an $\mathrm{EV}$ is used for driving and how much time it is parked at the household, which results in a spread of the revenue between 100 and $500 £$ /year with an average of $287 £ /$ year. It is necessary to analyse the frequency behaviour to get a realistic estimate of the earnings from frequency regulation, as it affects the cost of energy losses and the energy storage requirements. A charger efficiency of $90 \%$ results in an average cost of lost energy of $83 £ /$ year that reduces the profit with $30 \%$ to an average of $204 £ /$ year. The service results on average in $517 \%$ increase of the energy throughput of the EV battery. The throughput from frequency regulation is on average $6.7 \mathrm{MWh}$ per year, which for a 40 $\mathrm{kWh}$ battery corresponds to 83 full equivalent charge cycles, but can be up to twice as much depending on the usage.

\section{REFERENCES}

[1] C. Peng, J. Zou, and L. Lian, "Dispatching strategies of electric vehicles participating in frequency regulation on power grid: A review," Renewable and Sustainable Energy Reviews, 2017.

[2] A. Thingvad, S. Martinenas, P. Andersen, M. Marinelli, B. Christensen, and O. Olesen, "Economic comparison of electric vehicles performing unidirectional and bidirectional frequency control in denmark with practical validation," 2016 Proceedings of the 51st International Universities Power Engineering Conference, 2016.

[3] A. Thingvad, C. Ziras, and M. Marinelli, "Economic value of electric vehicle reserve provision in the nordic countries under driving requirements and charger losses," Journal of Energy Storage, 2019.

[4] A. Zecchino, A. Thingvad, P. B. Andersen, and M. Marinelli, "Test and modelling of commercial $\mathrm{v} 2 \mathrm{~g}$ chademo chargers to assess the suitability for grid services," World Electric Vehicle Journal, 2019.

[5] F. Prieta et al., Trends in Practical Applications of Scalable Multi-Agent Systems, the PAAMS Collection. springer, 2016.

[6] M. Petit and Y. Perez, "Vehicle-to-grid in France: What revenues for participation in frequency control?" International Conference on the European Energy Market, EEM, 2013.

[7] D. Dallinger, D. Krampe, and M. Wietschel, "Vehicle-to-grid regulation reserves based on a dynamic simulation of mobility behavior," IEEE Transactions on Smart Grid, vol. 2, 2011.

[8] P. B. Andersen, T. Sousa, A. Thingvad, L. S. Berthou, and M. Kulahci, "Added value of individual flexibility profiles of electric vehicle users for ancillary services," 2018.

[9] H. Christiansen, "Dtu transport - the data and model centre, the danish national travel survey," 2019.

[10] Department for Transport, "National Travel Survey: England," 2017.

[11] L. Calearo, A. Thingvad, K. Suzuki, and M. Marinelli, "Grid loading due to ev charging profiles based on pseudo-real driving pattern and user behaviour," IEEE Transactions on Smart Grid, 2019.

[12] Eurostat, "Electricity prices statistics," 2019.

[13] A. Thingvad, C. Ziras, J. Hu, and M. Marinelli, "Assessing the energy content of system frequency and electric vehicle charging efficiency for ancillary service provision," Proceedings of the 51st International Universities Power Engineering Conference, 2017.

[14] A. Thingvad and M. Marinelli, "Influence of v2 $\mathrm{g}$ frequency services and driving on electric vehicles battery degradation in the nordic countries," in EVS31, 2018. 